\title{
RESISTÊNCIA DE GENÓTIPOS DE MILHO PIPOCA A DOENÇAS $^{1}$
}

\author{
Eduardo Sawazaki ${ }^{2}$ \\ Gisèle Maria Fantin ${ }^{3}$ \\ Christina Dudienas ${ }^{2}$ \\ Jairo Lopes de Castro ${ }^{4}$ \\ Guido de Sordi ${ }^{5}$
}

\section{RESUMO}

Doze híbridos exóticos de milho pipoca, provenientes de várias empresas norte americanas, e mais cinco genótipos adaptados às condições ambientais do Brasil, foram avaliados quanto a resistência às principais doenças de ocorrência natural no Estado de São Paulo. Realizaram-se três ensaios, em condições de campo, nas regiões norte, centro e sul do estado, no ano agrícola 1993/94.

Os híbridos de milho pipoca norte americanos mostraram, em geral, boa adaptação em São Paulo mas, de maneira semelhante aos genótipos já introduzidos, também apresentaram elevada suscetibilidade às doenças. $\mathrm{O}$ enfezamento foi a doença que mais afetou a produtividade tanto dos genótipos exóticos como locais. Apresentaram menor intensidade desta doença os genótipos IAC 64 e IAC TC. Estes também apresentaram elevada resistência à queima de turcicum. Todos os genótipos mostraram alta suscetibilidade à ferrugem polissora. Apesar da baixa severidade da mancha de Phaeosphaeria nos ensaios, foi possível observar que o híbrido exótico HW 236 destacou-se entre os mais resistentes.

\footnotetext{
${ }^{1}$ Apresentado ao XXII Congresso Nacional de Milho e Sorgo, Recife, 1998.

${ }^{2}$ Instituto Agronômico-APTA, Caixa Postal 28, 13001-970, Campinas-SP. E-mail: sawazaki@iac.sp.gov.br

${ }^{3}$ Instituto Biológico-APTA, Caixa Postal 70, 13001-970, Campinas-SP. E-mail: gisele@biologico.sp.gov.br

${ }^{4}$ Pólo Regional da APTA Sudoeste Paulista, Caixa Postal 62, 18300-970, Capão Bonito-SP. ${ }^{5}$ Pólo Regional da APTA Centro Leste, Caixa Postal 271, 14001-970, Ribeirão Preto-SP.
} 
Palavras-chave: milho pipoca, Zea mays, doenças, enfezamento, Phaeosphaeria maydis, Exserohilum turcicum, Puccinia polissora.

\section{ABSTRACT}

\section{RESISTANCE OF POPCORN GENOTYPES AGAINST DISEASES}

Twelve foreign hybrids of popcorn, produced by several maize breeding companies of USA, and five genotypes already adapted to Brazilian environmental conditions, were screened to evidence resistance against the main diseases of natural occurrence under the conditions of State of São Paulo, Brazil. Three experiments were carried out, under field conditions, at the north, center and south regions of this State, during the season 1993/94.

The popcorn hybrids from USA exhibited good adaptation to these new conditions but, as the adapted genotypes, showed high susceptibility to the diseases. The maize bushy stunt/corn stunt was the most important disease concerning to productivity decrease of the genotypes. IAC 64 and IAC TC had the lowest intensity of this disease. These two genotypes showed also high resistance to northern leaf blight. All the genotypes were very susceptible to southern rust. Despite of the low severity of Phaeosphaeria leaf spot on the trials, it was noticed that the foreign hybrid HW 236 was pointed out among the most resistant genotypes to this disease.

Key words: popcorn, Zea mays, disease, maize bushy stunt, corn stunt, Phaeosphaeria maydis, Exserohilum turcicum, Puccinia polissora.

\section{INTRODUÇÃO}

O consumo de grãos de milho pipoca importados da Argentina e dos Estados Unidos da América aumentou gradativamente no Brasil até o final da década de 90 , chegando a mais de $50 \%$ do consumo nacional. Nestes últimos anos, a importação vem sendo substituída pela produção nacional obtida com sementes importadas de híbridos norte americanos. 
Essa importação está sendo realizada principalmente pela Yoki Alimentos S.A., cuja produção brasileira de grãos evoluiu de 5 mil toneladas em 1999 para perto de 30 mil toneladas em 2002 (Fávaro, 2002).

Híbridos norte americanos têm mostrado boa adaptação em algumas regiões do país (Heidrich Sobrinho \& Zanette, 1979; Merlo et al., 1988), principalmente em plantios antecipados ao período da safra normal (Sawazaki et al., 2000). São ainda excelentes materiais para serem utilizados nos programas de melhoramento da qualidade de variedades adaptadas (Sawazaki, 1995).

As variedades de milho pipoca existentes, pelo fato de serem menos rústicas em comparação ao milho comum, comumente apresentam elevada suscetibilidade a doenças. Apesar disto, existem poucos trabalhos realizados sobre doenças neste tipo de milho no Brasil. Alta intensidade de doenças em milho pipoca vem sendo observada há várias décadas, principalmente em relação à queima foliar de turcicum, causada por Exserohilum turcicum (Santiago \& Bullow, 1978, Fantin et al., $1991 \mathrm{e}$ Soares et al., 1993) e à ferrugem comum, cujo agente causal é Puccinia sorghi (Balmer \& Pereira, 1987; Pinto, 1997). Ambas as doenças são favorecidas por temperaturas amenas, as quais ocorrem comumente em culturas semeadas de agosto a setembro, principalmente na região sul do estado, época em que é mais freqüente a semeadura do milho pipoca.

A partir do início da década de 1990 , com o agravamento de doenças na cultura do milho, principalmente nas regiões onde se cultiva o milho verão e safrinha (Silva et al., 1994) o problema de doenças em pipoca tornou-se muito mais grave. A mancha de feosféria (Phaeophaeria maydis), que ocorria em geral no fim do ciclo da cultura, tornou-se problema e com frequiência afeta a produção de grãos em cultivares suscetíveis (Fantin, 1994; Menten et al., 1996). Esta é uma doença bastante favorecida por umidade elevada (Sawazaki et al., 1997). O enfezamento, que incidia de forma restrita, também se agravou, passando a causar danos à produtividade (Fernandes \& Oliveira, 1997; Duarte et al., 1999; Massola et al., 1999) São referidos de forma genérica como enfezamentos, tanto o enfezamento vermelho (associado a um fitoplasma) como o pálido (cujo agente causal é um espiroplasma - Spiroplasma kunkelii). Os patógenos destas doenças são transmitidos pela cigarrinha Dalbulus maidis em infecções separadas ou conjuntas, causando sintomas 
mais acentuados quanto mais cedo a planta for infectada, podendo acarretar desde avermelhamento ou amarelecimento foliar até nanismo acentuado da planta com formação de numerosas espigas pequenas e improdutivas (Shurtleff, 1992; Oliveira et al., 2002). Desta forma, a resistência ao enfezamento também pode ser evidenciada pela capacidade dos genótipos atacados em granar as espigas, completando o seu desenvolvimento. Na década de 1990, a ferrugem polissora, causada por Puccinia polysora (Fantin et al., 1992; Fantin, 1997) e a ferrugem tropical, cujo agente causal é Physopella zeae (Carvalho, 1995; Dudienas et al., 1997), passaram a se evidenciar, ambas acarretando epidemias na cultura do milho. Estas doenças são favorecidas por temperatura elevada a moderada, predominantes da região norte do Estado de São Paulo. Entre as doenças do milho, a ferrugem polissora é uma das mais destrutivas.

Pela carência de informações sobre reação a doenças em milho pipoca, este trabalho teve o objetivo de avaliar o comportamento de doze híbridos exóticos de milho pipoca provenientes de várias empresas norte americanas e de cinco cultivares adaptados às condições brasileiras, quanto a resistência às principais doenças de ocorrência natural, nas condições do Estado de São Paulo, visando identificar os mais promissores para serem utilizados nos programas de melhoramento.

\section{MATERIAL E MÉTODOS}

Foram instalados três ensaios de campo em Estações Experimentais da Secretaria de Agricultura e Abastecimento do Estado de São Paulo localizadas em Campinas (região centro), Capão Bonito (região sul) e Ribeirão Preto (região norte). Os ensaios de Campinas e Capão Bonito foram semeados em novembro de 1993, onde foram comparados, além da resistência às doenças da parte aérea, os principais caracteres agronômicos. O experimento de Ribeirão Preto foi semeado em dezembro de 1993, o qual foi realizado especificamente para a avaliação da resistência das plantas às doenças.

Os tratamentos consistiram de doze híbridos americanos provenientes de seis empresas de sementes de milho pipoca dos Estados Unidos da América (HW 115, HW 236, Exp. 8383, Exp. 62217, P 612, P 
615, M 910, A 2201, A 3045, A 5501, ASX 7 e ME 453) e mais cinco materiais adaptados, abrangendo um híbrido triplo (Zélia), um híbrido intervarietal (CO Pop 01), um "top-cross" (IAC TC) e duas variedades (IAC SAM e IAC-64). Foram utilizados em cada experimento 16 genótipos de milho pipoca, sendo que os híbridos IAC 64, CO Pop 01 e IAC TC não foram incluídos nos ensaios de Campinas, Capão Bonito e Ribeirão Preto, respectivamente. Em Ribeirão Preto, além dos 16 genótipos de milho pipoca, foram também incluídas duas testemunhas: os híbridos de milho ICI 8568 e Pioneer 3069, considerados, respectivamente, como resistente e suscetível à ferrugem polissora.

Utilizou-se o delineamento de blocos casualizados, sendo as parcelas constituídas por quatro fileiras de 5,0 m espaçadas a $0,9 \mathrm{~m}$ entre linhas, com três repetições (consideradas as duas fileiras centrais como parcela útil), para os ensaios de Campinas e Capão Bonito e parcelas de uma fileira de 3,0 m com duas repetições para o ensaio de Ribeirão Preto.

A intensidade das doenças foi avaliada quando o milho se encontrava na fase final do enchimento de grãos, aproximadamente 90 dias após a semeadura. As manchas foliares e ferrugens foram avaliadas em 5 plantas ao acaso de cada fileira útil. Para a mancha de feosféria e ferrugens, a avaliação foi realizada atribuindo-se notas de 1 a 9 às plantas, correspondendo a $0 ; 1 ; 2,5 ; 5 ; 10 ; 25 ; 50 ; 75$ e maior que $75 \%$ de área foliar afetada, respectivamente, com auxílio da escala diagramática Agroceres (Agroceres, 1993). Para a queima de turcicum, foram atribuídas notas de 1 a 6 às plantas, onde $1=$ altamente resistente e $6=$ altamente suscetível, segundo a escala diagramática de Chester (1950). A avaliação do enfezamento, em Ribeirão Preto, foi feita contagem e posterior determinação da porcentagem de plantas doentes; em Capão Bonito procurou-se identificar os materiais menos afetados, uma vez que a maioria dos genótipos apresentaram cerca de $100 \%$ das plantas com sintomas de descoloração foliar causada pela doença, atribuindo-se a cada parcela uma nota, através de uma escala de notas de 1 a 10 , elaborada especialmente para avaliação deste ensaio, onde $1=$ ausência de sintomas da doença, $2=20 \%$ de plantas com sintomas leves, $3=50 \%$ de plantas com sintomas, $4=80 \%$ de plantas com sintomas, $5=100 \%$ de plantas com sintomas, $6=100 \%$ de plantas com sintomas sendo $10 \%$ 
com sintomas severos, $7=100 \%$ de plantas com sintomas sendo $25 \%$ com sintomas severos, $8=100 \%$ de plantas com sintomas sendo $40 \%$ com sintomas severos, $9=100 \%$ de plantas com sintomas sendo $70 \%$ com sintomas severos e $10=100 \%$ de plantas com sintomas severos.

Nos ensaios de Campinas e Capão Bonito foram avaliados também os seguintes caracteres agronômicos: estande final, altura da planta, número total de espigas, peso de espigas e de grãos e umidade dos grãos. Em Campinas avaliou-se também o número de espigas doentes.

Realizou-se análise de variância da intensidade de doenças e das características agronômicas. A comparação de médias de tratamentos foi feita pelo teste de Tukey a $5 \%$, sendo que os dados de porcentagem de espigas afetadas foram transformados em $\sqrt{x}$ para análise estatística e os dados do enfezamento em Ribeirão Preto em $\sqrt{x+0,5}$. O peso de grãos foi corrigido para 14,5\% de umidade e para 53 plantas/parcela em Campinas e 39 em Capão Bonito. A correção dos dados de peso de grãos e do estande médio foi feita utilizando o método da covariância, segundo orientação de Vencovsky e Barriga (1992). Foram obtidos também coeficientes de correlação simples entre produtividade dos genótipos e intensidade de doenças.

\section{RESULTADOS E DISCUSSÃO}

$\mathrm{Na}$ Tabela 1 estão apresentados os resultados obtidos no experimento em Campinas. Observou-se alta produtividade de grãos em todos os genótipos devido às condições favoráveis de solo e clima, aliadas à baixa severidade das doenças. Diferenças entre os tratamentos foram observadas para todas as variáveis estudadas.

O genótipo IAC TC foi o mais prolífico e produtivo, diferenciando do Zélia que teve a segunda maior média de produção de grãos e que não diferiu dos híbridos norte americanos HW 115, ASX 7, ME 453, P 612, A 3045, P 615 e A 2201 e do híbrido local CO Pop 01. O menos adaptado foi o híbrido exótico M 910, que não diferiu da variedade SAM e dos híbridos Exp. 62217 e Exp. 8383.

Em relação à altura de plantas, os híbridos norte americanos apresentaram, como característica favorável, menores médias que os genótipos adaptados IAC TC, SAM e Zélia, os quais foram os mais 
을

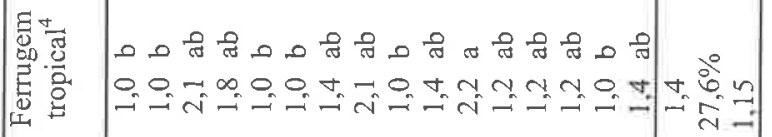

8

过

ษ

\% 9

.

은

0

$0 \frac{\pi}{\circ}$

을

'응

of

$\exists$ ส

a

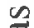

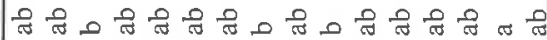
तं

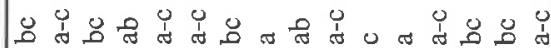

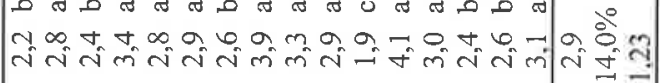

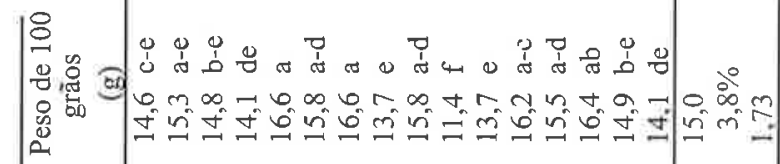

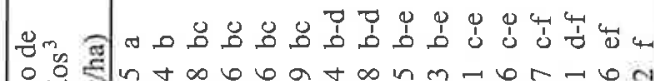
$\infty$

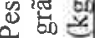

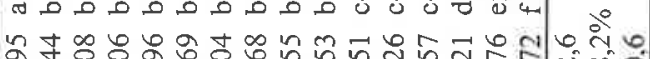

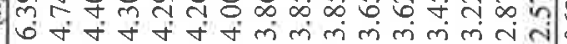

|

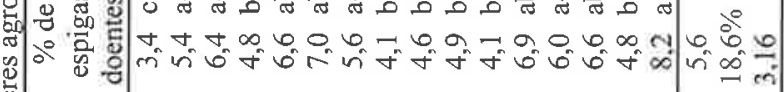

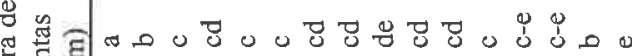

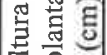
$\infty$ 更 正

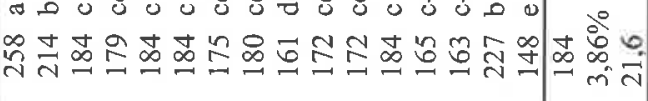

\section{o $m \frac{\pi}{2}$}

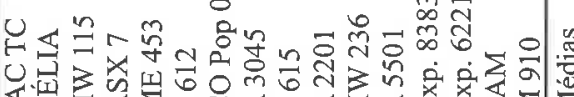

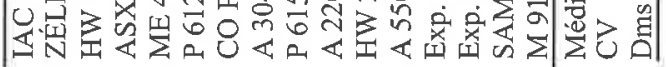


altos. Entre os exóticos, apresentaram menor porte os híbridos M 910 e P 615.

Maior sanidade de espigas foi observada no IAC TC, cuja média não diferiu dos outros genótipos adaptados e de sete dos exóticos. Entre os híbridos exóticos, os que apresentaram sanidade de espigas que mais se aproximou do IAC TC foram: A 3045, HW 236, P 615 e ASX 7. Observou-se alta porcentagem de espigas doentes, cerca de $67,2 \%$, no híbrido M 910.

As doenças apresentaram intensidade moderada a baixa em Campinas, sendo observadas a mancha de feosféria, as ferrugens comum e tropical e a queima de turcicum. Entre estas, a mancha de feosféria apresentou intensidade um pouco maior. Destacaram-se entre os genótipos mais resistentes a esta doença: HW 236, IAC TC, HW 115 e Exp. 62217. Não foi observada correlação significativa entre a severidade da mancha de feosféria e a produtividade $(r=-0,23)$ provavelmente pela moderada intensidade de ocorrência.

No ensaio instalado em Capão Bonito, diferentemente do de Campinas, houve ocorrência de doenças com alta intensidade causando elevados danos à produtividade (Tabela 2). Diferenças entre os genótipos também foram observadas para os outros caracteres agronômicos estudados. O híbrido adaptado IAC TC foi o mais prolífico e produtivo, seguido da variedade IAC 64 que foi superior aos demais genótipos, à exceção do ASX 7, A 3045 e ME 453. O peso de 100 grãos foi bem menor que o observado em Campinas devido aos danos causados pelas doenças, sendo que o híbrido M 910 apresentou tamanho de grão um pouco maior que os demais, mas diferindo apenas do Zélia e do A 2201.

As doenças que ocorreram em Capão Bonito foram o enfezamento e a queima de turcicum. O enfezamento ocorreu com intensidade bastante elevada, sendo que a maioria dos genótipos apresentou a totalidade das plantas com sintomas de avermelhamento/amarelecimento foliar, típico da doença. Destacou-se pela severidade um pouco menor ao enfezamento a variedade IAC 64 e o "top cross" IAC TC, os quais também se sobressaíram entre os mais produtivos. Houve também influência da doença no desenvolvimento de espigas com grãos, que pode ser observado neste ensaio pelo número abaixo de 1 de espigas por planta para a maioria dos genótipos. A influência desta doença na produtividade 


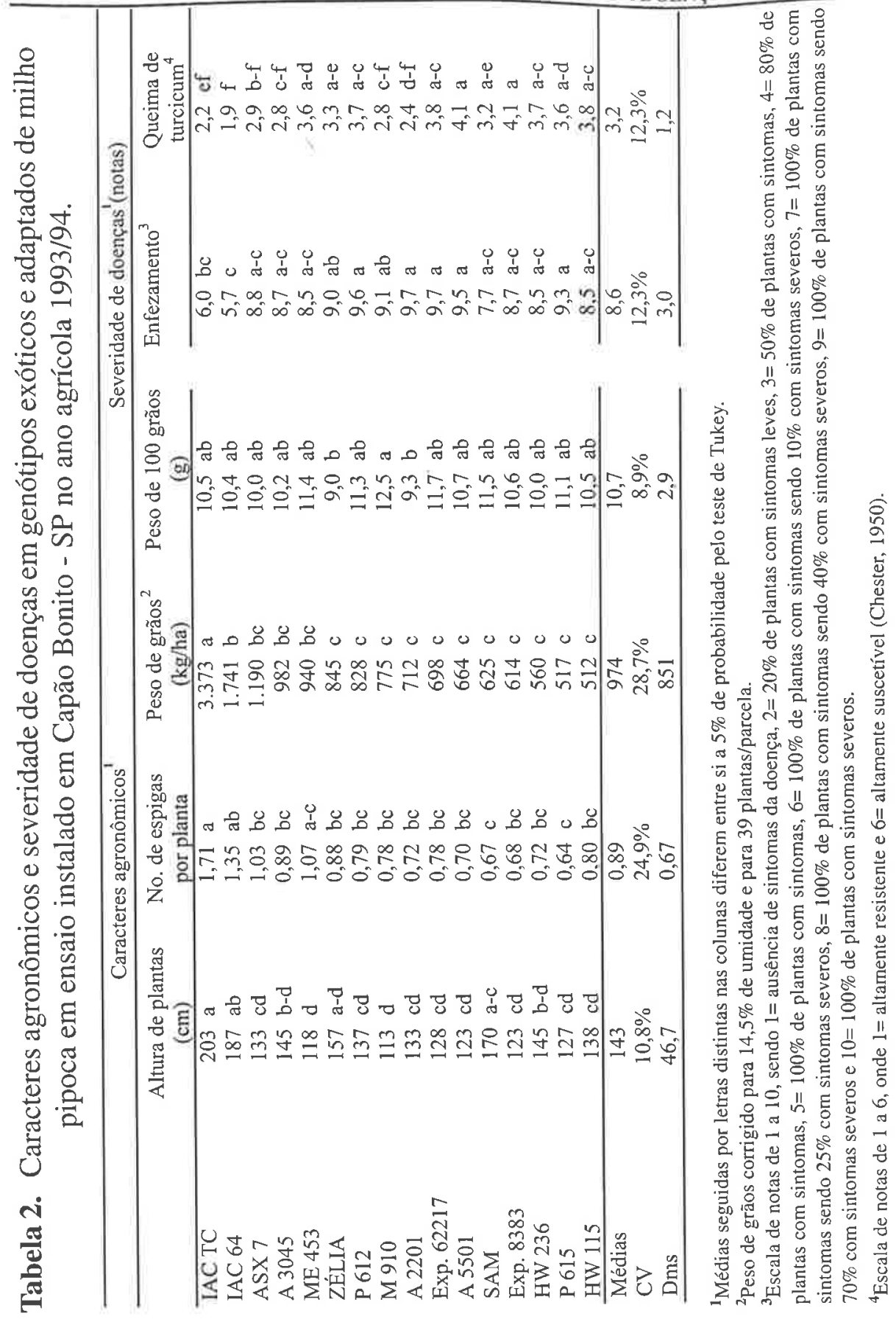


pode ser confirmada pela alta correlação negativa entre estas duas variáveis $(\mathrm{r}=-0,75 \mathrm{com} \mathrm{p}=0,0008)$.

A queima de turcicum também ocorreu com intensidade elevada neste ensaio. Os dois genótipos que apresentaram menor severidade a esta doença, IAC TC e o IAC 64, foram os que se destacaram entre os mais produtivos. A menor severidade desta doença pode ter contribuído para a maior produtividade destes materiais, pois foi encontrada correlação negativa, embora com valor menor, desta doença com a produtividade $(\mathrm{r}=-0,65$ com $\mathrm{p}=0,006)$.

Em Ribeirão Preto, onde a semeadura foi mais tardia, ocorreram as ferrugens polissora e tropical, a mancha de feosféria e o enfezamento (Tabela 3). Neste ensaio, o enfezamento teve baixa incidência.

A ferrugem polissora foi a doença que ocorreu com maior severidade neste ambiente. O híbrido P 612 apresentou menor severidade, seguido por Exp. 8383, ME 453 e CO Pop 01, indicando resistência um pouco maior destes genótipos a esta ferrugem.

Quanto à ferrugem tropical, observou-se pequena severidade nos híbridos A 2201 e Exp. 62217, embora não tenham sido encontradas diferenças significativas entre os materiais estudados, possivelmente pela interferência de outras doenças, como a ferrugem polissora, que é bastante destrutiva.

A incidência da ferrugem comum foi muita baixa em todos os locais, tendo sido avaliada apenas em Campinas (Tabela 1), onde se observou que os genótipos HW 115, A 2201 e A 3045 apresentaram menor severidade. A pequena quantidade desta doença era esperada pois ela é desfavorecida pelas condições de temperaturas mais elevadas que comumente ocorrem durante o ciclo da cultura semeada nos meses de novembro e dezembro.

Para a mancha de feosféria, que ocorreu nos ensaios de Campinas e de Ribeirão Preto (Tabelas 1 e 3), foi possível observar que os híbridos A 5501 e A 3045 apresentaram maior suscetibilidade a esta doença, embora não tenham diferido estatisticamente de vários outros genótipos testados. Por outro lado, embora em Campinas os híbridos HW 236, IAC TC, HW 115 e Exp. 62217 tenham se destacado entre os mais resistentes a esta doença, em Ribeirão Preto, onde a severidade média do ensaio foi apenas ligeiramente inferior, a doença não foi observada 
Tabela 3. Intensidade de doenças em genótipos exóticos e adaptados de milho pipoca em ensaio instalado em Ribeirão Preto no ano agrícola 1993/94.

\begin{tabular}{lccccc}
\hline & Incidência $^{1,2}$ & \multicolumn{4}{c}{ Severidade de doenças $^{1,3}$} \\
\cline { 3 - 6 } Genótipos & de enfezanento & Mancha de feosféria & Ferrugem polissora & Ferrugem tropical \\
\hline HW 115 & $1,8 \mathrm{ab}$ & $2,3 \mathrm{ab}$ & $5,3 \mathrm{ab}$ & 3,0 \\
HW 236 & $1,4 \mathrm{ab}$ & $1,0 \mathrm{~b}$ & $5,0 \mathrm{ab}$ & 3,3 \\
Exp. 8383 & $1,2 \mathrm{ab}$ & $1,0 \mathrm{~b}$ & $3,5 \mathrm{bc}$ & 5,0 \\
Exp. 62217 & $1,1 \mathrm{ab}$ & $2,5 \mathrm{ab}$ & $4,5 \mathrm{ab}$ & 2,8 \\
P 612 & $1,9 \mathrm{ab}$ & $2,5 \mathrm{ab}$ & $3,3 \mathrm{bc}$ & 3,8 \\
P 615 & $1,6 \mathrm{ab}$ & $1,5 \mathrm{ab}$ & $4,0 \mathrm{a}-\mathrm{c}$ & 4,8 \\
M 910 & $2,5 \mathrm{a}$ & $2,0 \mathrm{ab}$ & $5,8 \mathrm{ab}$ & 3,8 \\
A 2201 & $2,2 \mathrm{ab}$ & $2,0 \mathrm{ab}$ & $7,0 \mathrm{a}$ & 2,8 \\
A 3045 & $1,0 \mathrm{ab}$ & $3,5 \mathrm{ab}$ & $6,8 \mathrm{a}$ & 3,3 \\
A 5501 & $0,7 \mathrm{~b}$ & $4,8 \mathrm{a}$ & $5,8 \mathrm{ab}$ & 3,0 \\
ASX 7 & $1,5 \mathrm{ab}$ & $2,5 \mathrm{ab}$ & $5,8 \mathrm{ab}$ & 3,0 \\
ME 453 & $1,6 \mathrm{ab}$ & $1,8 \mathrm{ab}$ & $3,5 \mathrm{bc}$ & 3,8 \\
ZÉLIA & $2,1 \mathrm{ab}$ & $2,5 \mathrm{ab}$ & $4,5 \mathrm{ab}$ & 3,0 \\
CO Pop 01 & $1,0 \mathrm{ab}$ & $1,5 \mathrm{ab}$ & $3,5 \mathrm{bc}$ & 4,5 \\
SAM & $2,3 \mathrm{ab}$ & $2,0 \mathrm{ab}$ & $5,5 \mathrm{ab}$ & 3,5 \\
IAC-64 & $1,2 \mathrm{ab}$ & $1,3 \mathrm{ab}$ & $5,3 \mathrm{ab}$ & 3,3 \\
ICI 8568 $\left(\mathrm{TR}^{4}\right)$ & $0,7 \mathrm{~b}$ & $1,5 \mathrm{ab}$ & $1,0 \mathrm{c}$ & 2,8 \\
P 3069 (TS $\left.{ }^{4}\right)$ & $1,3 \mathrm{ab}$ & $1,0 \mathrm{~b}$ & $4,8 \mathrm{ab}$ & 3,5 \\
\hline Médias & 1,5 & 2,1 & 4,7 & 3,5 \\
CV & $29,8 \%$ & $40,0 \%$ & $16,9 \%$ & $16,7 \%$ \\
Dms & 1,8 & 3,3 & 3,2 & 2,4 \\
\hline
\end{tabular}

'Médias seguidas por letras distintas na mesma coluna diferem entre si a $5 \%$ de probabilidade pelo teste de Tukey. ${ }^{2}$ Dados originais de porcentagem de plantas doentes transformados em $\sqrt{x+0,5}$.

${ }^{3}$ Escala de notas de 1 a 9 correspondendo a $0 ; 1 ; 2,5 ; 5 ; 10 ; 25 ; 50 ; 75$ e mais de $75 \%$ de área foliar afetada (Agroccres, 1993).

${ }^{4} \mathrm{TR}=$ testemunha, hibrido de milho resistente a ferrugem polissora; TS = testemunha, hibrido de milho suscetivel a ferrugem polissora.

nos genótipos HW 236 e no Exp. 8383. Este último híbrido apresentou severidade moderada em Campinas. Os resultados obtidos no presente estudo estão de acordo com os encontrados em estudos feitos por Fantin et al. (1999) e por Brunelli et al. (2002) que também observaram cultivares de milho que se mostraram comparativamente mais resistentes que os demais genótipos em um local que outro, indicando uma possível variabilidade do patógeno. 


\section{CONCLUSÕES}

O enfezamento foi a doença que mais afetou a produtividade dos genótipos exóticos' e locais, tendo apresentado maior resistência os genótipos IAC 64 e IAC TC, que também se sobressaíram quanto a resistência à queima de turcicum.

Todos os genótipos de milho pipoca mostraram alta suscetibilidade à ferrugem polissora, sendo que alguns apresentaram severidade da doença maior que o híbrido de milho comum P 3069, considerado altamente suscetível.

Apesar da baixa severidade da mancha de feosféria nos ensaios, o híbrido exótico HW 236 destacou-se entre os mais resistentes a essa doença.

Anexo 1. Análise de variância utilizando o programa Sanest, do ensaio de Campinas, 93/94.

\begin{tabular}{|l|c|l|l|l|l|l|l|}
\hline $\begin{array}{c}\text { F. } \\
\text { Variação }\end{array}$ & GL & $\begin{array}{c}\text { QM } \\
\text { ED( \%) }\end{array}$ & $\begin{array}{c}\text { QM } \\
\text { Phaeosph }\end{array}$ & $\begin{array}{c}\text { QM } \\
\text { P.sorghi }\end{array}$ & $\begin{array}{c}\text { QM } \\
\text { E.furcic }\end{array}$ & $\begin{array}{c}\text { QM } \\
\text { P100G }\end{array}$ & $\begin{array}{c}\text { QM } \\
\text { Physop. }\end{array}$ \\
\hline Blocos & 2 & 1,0634 & 0,4390 & 0,1702 & 0,4077 & 1,0752 & 0,0889 \\
\hline Trat. & 15 & $5,2304^{* *}$ & $1,0114^{* *}$ & $0,1786^{* *}$ & $0,1591^{* *}$ & $5,6998^{* *}$ & $0,5828^{* *}$ \\
\hline Resíduo & 30 & 1,0778 & 0,1645 & 0,06331 & 0,0495 & 0,3217 & 0,1432 \\
\hline CV & & 18,63 & 14,03 & 13,04 & 15,52 & 3,79 & 57,6 \\
\hline $\begin{array}{l}\text { Dms (Tukey a } \\
5 \%)\end{array}$ & & 3,16 & 1,23 & 0,77 & 0,63 & 1,73 & 1,15 \\
\hline
\end{tabular}

\begin{tabular}{|lcl|ll|}
\hline \multicolumn{1}{|c}{ F. } & \multicolumn{1}{c|}{ QM } & \multicolumn{1}{c|}{ QM } & \multicolumn{1}{c|}{ QM } \\
Variação & GL & \multicolumn{1}{c|}{ PG } & \multicolumn{1}{c|}{ AP } & \multicolumn{1}{c|}{ NE } \\
Blocos & 2 & 127104,02 & 146,6565 & 0,0040 \\
Trat. & 15 & $2243046,31^{* *}$ & $2240,4924^{* *}$ & $0,1146^{* *}$ \\
Residuo & 30 & 106006,58 & 50,6253 & 0,0197 \\
C.V. & & 8,22 & 3,86 & 11,3 \\
\hline Dms (Tukey a & & & & \\
$5 \%$ ) & & 990,6 & 21,65 & 0,43 \\
\hline
\end{tabular}


Anexo 2. Análise de variância do ensaio em Capão Bonito, 93/94.

\begin{tabular}{|l|c|l|l|l|l|l|l|}
\hline \begin{tabular}{|l|} 
F \\
Variação
\end{tabular} & $\mathrm{GL}$ & \multicolumn{1}{|c|}{$\begin{array}{c}\mathrm{QM} \\
\mathrm{PG}\end{array}$} & $\begin{array}{c}\text { QM } \\
\text { E.turcic }\end{array}$ & $\begin{array}{c}\text { QM } \\
\text { Enfezam. }\end{array}$ & $\begin{array}{r}\text { QM } \\
\mathrm{AP}\end{array}$ & $\begin{array}{r}\text { QM } \\
\text { NE }\end{array}$ & $\begin{array}{c}\text { QM } \\
\text { P100G }\end{array}$ \\
\hline Blocos & 2 & 102753,19 & 0,1502 & 5,005 & 377,083 & 0,1848 & 1,0557 \\
\hline Trat. & 15 & $1511724,61^{* *}$ & $1,3610^{* *}$ & $4,2552^{* *}$ & $1892,1875^{* *}$ & $0,2445^{* *}$ & $2,399^{*}$ \\
\hline Resíduo & 30 & 78173,08 & 0,1593 & 1,1135 & 235,4167 & 0,0489 & 0,8992 \\
\hline CV & 28,72 & 12,32 & 12,34 & 13,0 & 3,79 & 8,86 \\
\hline $\begin{array}{l}\text { Dms (Tukey } \\
\text { a 5\%) }\end{array}$ & 850,7 & 1,21 & 3,0 & 0,77 & 1,73 & 2,9 \\
\hline
\end{tabular}

Anexo 3. Quadro de análise de variância do ensaio de Ribeirão Preto, 93/94.

\begin{tabular}{|l|l|l|l|l|l|}
\hline $\begin{array}{c}\text { F. } \\
\text { Variação }\end{array}$ & GL & $\begin{array}{c}\text { QM } \\
\text { P.polysona }\end{array}$ & \multicolumn{1}{c|}{$\begin{array}{c}\text { QM } \\
\text { Phaeosph. }\end{array}$} & $\begin{array}{c}\text { QM } \\
\text { Enfezam. }\end{array}$ & \multicolumn{1}{c|}{$\begin{array}{c}\text { QM } \\
\text { Physop. }\end{array}$} \\
\hline Blocos & 1 & 1,3611 & 0,0278 & 0,0173 & 0,0278 \\
\hline Trat. & 17 & $4,096^{* *}$ & $1,7876^{*}$ & $0,6015^{*}$ & $0,9248^{*}$ \\
\hline Resíduo & 30 & 0,6258 & 0,6748 & 0,2035 & 0,3366 \\
\hline CV & & 16,9 & 40,0 & 29,8 & 16,7 \\
\hline $\begin{array}{l}\text { Dms (Tukey a } \\
5 \%)\end{array}$ & & 3,2 & 3,3 & 1,8 & 2,4 \\
\hline
\end{tabular}

\section{REFERÊNCIAS BIBLIOGRÁFICAS}

AGROCERES. Guia Agroceres de Sanidade. São Paulo, 1993. 56p. BALMER, E. \& PEREIRA, O.A.P. Doenças do Milho. In: PATERNIANI, E. \& VIEGAS, G.P. (Ed.) Melhoramento e Produção do Milho. 2.ed. Campinas: Fundação Cargill, 1987. v.2, cap.14, p.595-634.

BRUNELLI, K.R.; LOPES, R.; LOPES, M.T.G.; MATIELLO, R.R.; SILVA, H.P. \& CAMARGO, L.E.A. Reação de Genótipos de Milho a Phaeosphaeria maydis em diferentes Ambientes. Fitopatologia Brasileira, v.27, p.S88, 2002. Suplemento.

CARVALHO, R.V. Resistência do Milho a Physopella zeae (Mains) Cummins \& Ramachar, Agente Causal da Ferrugem Tropical. 
Piracicaba, 1995. 83p.. Dissertação (M.S.) - Escola Superior de Agricultura "Luiz de Queiroz", Universidade de São Paulo.

CHESTER, K.S. Plant Diseases Losses: Their Appraisal and Interpretation. Plant Disease Reporter, v.193, p.191-362, 1950. Supl.

DUARTE, A.P.; FANTIN, G.M.; DUDIENAS, C.; BORTOLETTO, N.; GELLER, C.; GALLO, P.B.; RECO, P.C.; BIANCHINI, M.T.; BOLONHEZI, D.; SILVEIRA, L.C.P. \&SABINO Jr; J. Incidência de Enfezamentos e Viroses em Cultivares de Milho no Estado de São Paulo nas Safrinhas de 1997 e 1998. In: SEMINÁRIO SOBRE A CULTURA DO MILHO SAFRINHA, 5., Barretos, 1999. Anais. Campinas: Instituto Agronômico, 1999. p.207-216.

DUDIENAS, C.; SAWAZAKI, E.; PATERNIANI, M.E.A.G.Z.; GALVÃO, J.C.C.; SORDI, G.D. \& PEREIRA, J. Comportamento de Cultivares de Milho, em Condições de Campo, quanto à Resistência à Physopella zeae. Summa Phytopathologica, v.23, n.3/4, p.259-262. 1997.

FANTIN, G.M. Avaliação de Resistência do Milho à Ferrugem causada por Puccinia polysora Underw. Piracicaba, 1997. 140p. Tese (Doutoramento) - Escola Superior de Agricultura "Luiz de Queiroz", Universidade de São Paulo.

FANTIN, G.M. Mancha de Phaeosphaeria, Doença do Milho que vem Aumentando sua Importância. Biológico, v.56, n. 1/2, p.39, 1990/ 1994.

FANTIN, G.M.; DUDIENAS, C.; DUARTE, A.P.; CAZENTINI FILHO, G.; RECO, P.C.; COICEV, L.; PATERNIANI, M.E.A.G.Z.; BORTOLETO, N. \& CASTRO, J.L. Ocorrência e Intensidade de Doenças em Cultivares de Milho. In: DUARTE, A.P. \& PATERNIANI, M.E.A.G.Z. (Coords.) Cultivares de Milho no Estado de São Paulo: Resultados das Avaliações Regionais IAC/ CATI/Empresas 1998/99. Campinas: Instituto Agronômico, 1999. p.35-56. (Documentos IAC, 66)

FANTIN, G.M.; SAWAZAKI, E. \& BARROS, B.C. Avaliação de Genótipos de Milho Pipoca quanto a Resistência a Doenças e Qualidade da Pipoca. Summa Phytopathologica, v.17, n.2, p.9099, 1991. 
FANTIN, G.M.; SAWAZAKI, E.; MEREGE, W.H.; DENUCCI, S.; EICHEL, O.A.C.; GALLO, P.B.; MARTINS, A.L.; CASTRO, J.L. \& SORDI, G. Teste Regional de Cultivares de Milho: Avaliação de Doenças. Fitopatologia Brasileira, v.17, n.2, p.173-174, 1992. FÁvARO, T. Yoki e BB Garantem Compra de Produção de Grãos e Mandioca. O Estado de São Paulo, 20/02/2002. Suplemento Agrícola, 2.415. p.3.

FERNANDES, F.T. \& OLIVEIRA, E. Principais Doenças na Cultura do Milho. Sete Lagoas: EMBRAPA-CNPMS, 1997. 80p. (Circular Técnica, 26)

HEIDRICH SOBRINHO, \& ZANETTE, V.A. Competição de Híbridos e Populações de Milho Pipoca no Rio Grande do Sul. Agronomia Sul Rio Grandense, v.15, n.1, 103-110, 1979.

MASSOLA, J.R.; BEDENDO, I.P.; AMORIM, L. \& LOPES, J.R.S. Incidência de Enfezamentos e Danos na Cultura do Milho. In: SEMINÁRIO SOBRE A CULTURA DO MILHO SAFRINHA, 5., Barretos, 1999. Anais. Campinas: Instituto Agronômico, 1999. p.175-195.

MENTEN, J.O.M.; PARADELA, A.L.; MARTINS, L.M.D. \& ARANTES, S.R.A. Reação de Genótipos de Milho à Phaeosphaeria maydis e Efeito na Produtividade. Ecossistema, v.21, p.72-74, 1996.

MERLO, E.; FORNASIER FILHO, D. \& LAM-SANCHES, A. Avaliação de Sete Cultivares de Milho Pipoca (Zea mays L.) em Três Densidades de Semeadura. Científica, v.16, n.2, p.245-251, 1988.

OLIVEIRA, E; OLIVEIRA, C.M. de.; SOUZA, I.R.P. de; MAGALHÃES, P.C. \& CRUZ, I. Enfezamentos em Milho: Expressão de Sintomas Foliares, Detecção dos Molicutes e Interações com Genótipos. Revista Brasileira de Milho e Sorgo, v.1, n.1, p.53-62, 2002.

PINTO, N.F.J. de A. Eficiência de Fungicidas no Controle de Doenças Foliares do Milho Pipoca. Summa Phytopathologica, v.23, n.3/ 4, p.271-274, 1997.

SANTIAGO, A.D. \& BULLOW, J.F.W. Competição de Três Variedades de Milho Pipoca no Distrito Federal. In: REUNIÃO BRASILEIRA 
DE MILHO E SORGO, 12, Goiânia, 1978. Anais, Brasília, EMBRAPA, 1979. P. 36.

SAWAZAKI, E. Melhoramento de Milho Pipoca. Campinas, Instituto Agronômico, 1995, 21p. (Documentos IAC, 53)

SAWAZAKI, E.; CASTRO, J.L.; GALO, P.B.; IGLESIAS, C. \&

JUNQUEIRA, M.T. Avaliação de Genótipos de Milho Pipoca em

Plantio Tardio e Antecipado em Dois Locais do Estado de São Paulo. Resumos, In: CONGRESSO NACIONAL DE MILHO E SORGO, 23., Uberlândia, 2000. Resumos. Sete Lagoas: ABMS/ Embrapa Milho e Sorgo/Universidade Federal de Uberlândia, 2000, . p.52.

SAWAZAKI, E.; DUDIENAS, C.; PATERNIANI, M.E.A.G.Z.; GALVÃO, J.C.C.; CASTRO, J,L. \& PEREIRA, J. Reação de Cultivares de Milho à Mancha de Phaeosphaeria no Estado de São Paulo. Pesq. Agropec. Bras., v.32, n.6, p.585-589, 1997. SHURTLEFF, M.C. (Ed.) Compendium of Corn Diseases. 2.ed. St. Paul: American Phytopathological Press, 1992. 105p.

SILVA, H.P.; REZENDE, I.C. \& PEREIRA, O.A.P. Comportamento das Doenças do Milho em Diferentes Épocas de Semeadura. In: CONGRESSO NACIONAL DE MILHO E SORGO, 20. Anais. 1994. p.173.

SOARES, A.M.Q.; LOPES, C.A. \& REIDSCHNEIDER, F.J.B. Avaliação de Populações de Milho-Pipoca para Resistência a Exserohilum turcicum. Hort. Bras. v.11, n.1, p.22-24, 1993. VENCOVSKY, R. \& BARRIGA, P. Genética Biométrica no Fitomelhoramento, Revista Brasileira de Genética, 1992. 496p. 